\title{
Hydroxyl (6-2) airglow emission intensity ratios for rotational temperature determination
}

\author{
W. J. R. French ${ }^{1,2}$, G. B. Burns ${ }^{1}$, K. Finlayson ${ }^{1}$, P. A. Greet ${ }^{1}$, R. P. Lowe ${ }^{3}$, P. F. B. Williams ${ }^{1}$ \\ ${ }_{2}^{1}$ Australian Antarctic Division, Kingston, Tasmania, Australia 7050 \\ 2 Institute of Antarctic and Southern Ocean Studies, University of Tasmania, Hobart, Tasmania, Australia, 7000 \\ ${ }^{3}$ Institute for Space and Terrestrial Science, University of Western Ontario, London, Canada N6A3K7
}

Received: 10 May 2000 / Accepted: 23 May 2000

\begin{abstract}
OH}(6-2) \mathrm{Q}_{1} / \mathrm{P}_{1}$ and $\mathrm{R}_{1} / \mathrm{P}_{1}$ airglow emission intensity ratios, for rotational states up to $j^{\prime}=4.5$, are measured to be lower than implied by transition probabilities published by various authors including Mies, Langhoff et al. and Turnbull and Lowe. Experimentally determined relative values of $j^{\prime}$ transitions yield $\mathrm{OH}(6-2)$ rotational temperatures $2 \mathrm{~K}$ lower than Langhoff et al., $7 \mathrm{~K}$ lower than Mies and $13 \mathrm{~K}$ lower than Turnbull and Lowe.
\end{abstract}

Key words: Atmospheric composition and structure (airglow and aurora; pressure, density and temperature)

\section{Introduction}

Hydroxyl airglow emissions are used extensively for studies of the upper mesosphere (e.g. Offermann and Gerndt, 1990; Sivjee, 1992; Scheer, 1995). The emissions originate from a layer near $87 \mathrm{~km}$ with a mean thickness of $8 \mathrm{~km}$ (Baker and Stair, 1988).

Rotational temperatures are derived by comparing the intensities of two or more lines from different upper rotational states, as per Eq. (1) (Mies, 1974). Transition probabilities are used to apportion the percentage of the upper rotational states that decay via the transitions measured.

$$
\mathrm{T}=\left[h c / k^{*}\left(F_{b}-F_{a}\right)\right] / \ln \left[\left\{I_{a} A_{b}\left(2 j_{b}^{\prime}+1\right)\right\} /\left\{I_{b} A_{a}\left(2 j_{a}^{\prime}+1\right)\right\}\right]
$$

$F_{a}, F_{b}$ are the energy levels of the initial rotational states (we use energy level values given by Coxon and Foster, 1982); $I_{a}, I_{b}$ are the emission intensities of the $\mathrm{OH}$ lines

Correspondence to: G. B. Burns

e-mail: gary_bur@antdiv.gov.au from different upper states; $A_{a}, A_{b}$ are the transition probabilities; $j_{a}^{\prime}, j_{b}^{\prime}$ are the upper state, total angular momentum quantum numbers; and $h, c$ and $k$ are Planck's constant, the speed of light and Boltzmann's constant respectively.

Hydroxyl bands are designated by transitions from an upper state, $v^{\prime}$ (=vibration quantum number), to a lower state, $v^{\prime \prime}$, as the $\mathrm{OH}\left(v^{\prime}-v^{\prime \prime}\right)$ band. The $\Delta v=2$ hydroxyl bands are the brightest. These occur in the near-infrared around 1.5 microns. As $\Delta v$ increases the bands become less intense and appear at lower wavelengths. Particular $\mathrm{OH}$ bands are popular depending on the upper wavelength limit of the detector. With a GaAs or cooled ccd detector the $\mathrm{OH}(6-2)$ band near $\lambda 840 \mathrm{~nm}$ is often preferred (e.g. Myrabo and Harang, 1988; Viereck and Deehr, 1989; Scheer, 1995; Hecht et al., 1995; Hobbs et al., 1996; Greet et al., 1998); see Takahashi and Batista (1981) for a comparison of $\mathrm{OH}$ bands in the vicinity of (6-2).

The transition probabilities of Nelson et al., (1990), used by researchers for low $\Delta v$ transitions (e.g. Lowe et al., 1991; Sivjee and Waltershied, 1994; Mulligan et al., 1995) do not cover the OH(6-2) band. Transition probabilities have been published that include the $\Delta v=4$ band (e.g. Mies, $1974=$ Mies; Turnbull and Lowe, $1989=$ T\&L; Langhoff et al., $1986=$ LWR). The larger the vibrational transition, the larger is the temperature variance from the choice of transition probabilities (T\&L). Greet et al. (1998) reported a $12 \mathrm{~K}$ variation in $\mathrm{OH}(6-2)$ temperatures depending on the choice of transition probabilities.

Intensity ratios of lines from the same upper state are constant, independent of temperature. We report measurements of line ratios from the four lowest quantum number rotational states of the $\mathrm{OH}(6-2)$ band for comparison with values inferred from Mies, LWR and T\&L (see Table 1). Ratios of transition probabilities (the $A_{a} / A_{b}$ values in Eq. 1) are experimentally derived from observations of the night sky. We also compare average temperatures derived from measurements of the four brightest $\mathrm{OH}(6-2) \mathrm{P}_{1}$-branch lines, using spectra recorded at Davis, Antarctica $\left(68.6^{\circ} \mathrm{S}, 78.0^{\circ} \mathrm{E}\right)$, and the 
Table 1. $\mathrm{Q}_{1} / \mathrm{P}_{1}$ and $\mathrm{R}_{1} / \mathrm{P}_{1}$ ratios inferred from Mies, LWR and $\mathrm{T} \& \mathrm{~L}$ compared with measured values

\begin{tabular}{llllll}
\hline$j^{\prime}$ & Ratio & T\&L & Mies & LWR & Experiment \\
\hline 1.5 & $\mathrm{Q}_{1}(1) / \mathrm{P}_{1}(2)$ & 1.42 & 1.365 & 1.33 & $1.261 \pm 0.012$ \\
2.5 & $\mathrm{Q}_{1}(2) / \mathrm{P}_{1}(3)$ & 0.49 & 0.46 & 0.44 & $0.389 \pm 0.006$ \\
3.5 & $\mathrm{Q}_{1}(3) / \mathrm{P}_{1}(4)$ & 0.244 & 0.228 & 0.213 & $0.173 \pm 0.011$ \\
4.5 & $\mathrm{Q}_{1}(4) / \mathrm{P}_{1}(5)$ & 0.145 & 0.132 & 0.123 & $0.094 \pm 0.004$ \\
5.5 & $\mathrm{Q}_{1}(5) / \mathrm{P}_{1}(6)$ & 0.094 & 0.086 & 0.078 & \\
& & & & & \\
2.5 & $\mathrm{R}_{1}(1) / \mathrm{P}_{1}(3)$ & 0.540 & 0.486 & 0.451 & $0.436 \pm 0.017$ \\
3.5 & $\mathrm{R}_{1}(2) / \mathrm{P}_{1}(4)$ & 0.678 & 0.590 & 0.523 & $0.510 \pm 0.010$ \\
4.5 & $\mathrm{R}_{1}(3) / \mathrm{P}_{1}(5)$ & 0.732 & 0.615 & 0.522 & $0.483 \pm 0.018$ \\
5.5 & $\mathrm{R}_{1}(4) / \mathrm{P}_{1}(6)$ & 0.756 & 0.613 & 0.500 & \\
\hline
\end{tabular}

transitional probabilities of Mies, LWR, T\&L and the experimentally determined $A_{a} / A_{b}$ ratios.

\section{Hydroxyl line nomenclature}

This description of hydroxyl line nomenclature is condensed from Osterbrock and Martel (1992) and Osterbrock et al. (1996, 1997). Lines within an hydroxyl band principally result from rotational state transitions within either the ground or first excited electronic state of the molecule. Rotational transitions within the excited state are about a third as intense as the equivalent ground state transition.

The hydroxyl electronic ground state is designated $\mathrm{X}^{2} \Pi_{3 / 2}$ and has electronic total angular momentum $\Omega=1.5$. The first excited state, $\mathrm{X}^{2} \Pi_{1 / 2}$, has $\Omega=0.5$. The total rotational angular momentum of the molecule, $j$, is the vector sum of $\Omega$ and the angular momentum of nuclear rotation. The total angular momentum of the hydroxyl molecule can be any integral value above the electronic total angular momentum. Thus the ground state has $j=1.5,2.5,3.5, \ldots$, and the first excited state has $j=0.5,1.5,2.5, \ldots$. Alternatively, the rotational states can be designated by the total molecular angular momentum apart from spin. This is designated $k$, and is an integral quantum number for describing the rotation states (used for example by Chamberlain, 1961). For the ground electronic state, $k=j-1 / 2$, and for the first excited state, $k=j+1 / 2$.

Quantum selection rules limit rotational quantum number transitions to -1 (P-branch), 0 (Q-branch) and +1 (R-branch). Thus we can describe ground state rotational transitions as: $\mathrm{OH}\left(v^{\prime}-v^{\prime \prime}\right) \mathrm{P}(\text { or } \mathrm{Q} \text {, or } \mathrm{R})_{1}\left(k^{\prime \prime}\right)$. Either the lower state rotational quantum number $k^{\prime \prime}$, or the upper state rotational quantum number $j^{\prime}$, have been commonly used to describe the transitions. We choose to use $k^{\prime \prime}$ as it is an integral value. The ' 1 ' subscript applies to a ground state transition. A ' 2 ' subscript implies a transition within the first excited state.

Each rotational line is further split by $\Lambda$-doubling into components depending on the parity of the electronic wave functions to reflections in a plane through the internuclear axis. These transitions are distinguished by subscripts $e$ and $f$, indicating the lower state parity. Thus, $\mathrm{OH}\left(v^{\prime}-v^{\prime \prime}\right) \mathrm{P}, \mathrm{Q}, \mathrm{R}_{1,2 e, f}\left(k^{\prime \prime}\right)$ distinguishes the $\Lambda$-components. Typically the $\Lambda$-components are spectrally close, but the separation increases as the $k^{\prime \prime}$ of the transition.

Weak transitions are possible between the two lowest electronic energy levels of the hydroxyl molecule. These are known as 'satellite' lines, and have been observed and reported (Turnbull and Lowe, 1983; Osterbrock et al., 1997; Greet et al., 1998). These are noted by a $\Delta k$ superscript preceding the $\Delta j$ descriptor. $\Delta k$ transitions ranging from -2 to +2 are possible and are designated $\mathrm{O}, \mathrm{P}, \mathrm{Q}, \mathrm{R}, \mathrm{S}$, in an expansion of the $\Delta j$ nomenclature. The electronic state transition is indicated by a double numeral suffix in a 'from - to' manner. Thus ${ }^{\mathrm{P}} \mathrm{Q}_{12}(2)$ indicates an electronic state transition from the ground state to the first excited state, with $\Delta k=-1$ and $\Delta j=0$, with the lower state having a $k$ quantum number of 2. Goldman (1982) gives transition probabilities for satellite lines relative to the Mies values for the main branch transitions. These are listed as ratios of the appropriate $\mathrm{OH}(6-2) \mathrm{P}_{1}$-branch line intensities in Table 2.

Upper rotational states may thus emit via three possible transitions within their initial electronic state, or via three weak transitions between electronic states. It is the relative proportions emitted via these possible transitions that is allowed for by the $A_{a} / A_{b}$ ratios of Eq. (1).

At some level of $j^{\prime}$, the rotation state populations become non-thermal (see e.g. Pendleton et al., 1993). States of high $j^{\prime}$ from one hydroxyl band may have wavelengths sufficiently different from the dominant band lines to extend into another band (see Osterbrock et al., 1997; Greet et al., 1998).

\section{Instrumentation and data}

A Czerny-Turner scanning spectrophotometer (CZT) has been run for a number of years at Davis, Antarctica $\left(68.6^{\circ} \mathrm{S}, 78.0^{\circ} \mathrm{E}\right)$. For the measurements reported here, the spectrophotometer had a six degree field-of-view (fov) in the zenith. A cooled $\left(-28{ }^{\circ} \mathrm{C}\right) \mathrm{GaAs}$ photomultiplier tube was used for photon detection. A blocking filter (rejects $\lambda<475 \mathrm{~nm}$ ) was used, limiting observations to the first order. The instrument is described more completely by Greet et al. (1998).

The spectral response was determined by scanning a low brightness source (LBS) which uniformly illuminated

Table 2. Satellite line ratios with respect to the appropriate P-branch line, as inferred from Goldman (1982)

\begin{tabular}{lllll}
\hline$j^{\prime}$ & Ratio & ${ }^{\mathrm{Q}} / \mathrm{P}$ & ${ }^{\mathrm{P}} \mathrm{Q} / \mathrm{P}$ & ${ }^{\mathrm{O}} \mathrm{P} / \mathrm{P}$ \\
\hline 1.5 & sat./ $\mathrm{P}_{1}(2)$ & 0.015 & 0.018 & 0.006 \\
2.5 & sat./ $\mathrm{P}_{1}(3)$ & 0.005 & 0.014 & 0.006 \\
3.5 & sat./ $\mathrm{P}_{1}(4)$ & 0.002 & 0.011 & 0.006 \\
4.5 & sat./ $\mathrm{P}_{1}(5)$ & 0.001 & 0.009 & 0.005 \\
5.5 & sat./P $(6)$ & 0.000 & 0.008 & 0.004 \\
\hline
\end{tabular}


the CZT fov. The LBS was calibrated against a spectral standard by the Australian Measurement Laboratories. The CZT was used to spectrally scan the LBS a total of 121 times on five separate occasions throughout the 1997 observation season (February-October). The LBS intensities at $\lambda 828 \mathrm{~nm}$ and $\lambda 851 \mathrm{~nm}$, the largest separation of lines compared, yielded a consistent ratio over the year to within $0.24 \%$. An average instrument response is suitable for the entire 1997 data set.

The operating mode for determining $\mathrm{OH}$ rotational temperatures during 1997 consisted of successively scanning narrow wavelength intervals incorporating the $\mathrm{OH}(6-2) \quad \mathrm{P}_{1}(2), \mathrm{P}_{1}(4)$ and $\mathrm{P}_{1}(5)$ emissions and appropriate background regions. Entrance and exit slit separations of 250 microns were used. Between day-ofyear (DOY) 182-229, 1997, additional wavelength regions were successively incorporated, to measure the intensities needed to determine the low rotational quantum number $\left(j^{\prime} \leq 4.5\right)$ line ratios. A step size of $0.01 \mathrm{~nm}$ and a dwell-time of $1 \mathrm{~s}$ were used. Between DOY 230-295, the slit separations were narrowed to 100 microns, reducing the width of the instrument function. This is near the limit to which reasonable parallelism of the entrance and exit slits can be maintained for this instrument. The step size was reduced to $0.005 \mathrm{~nm}$ and a dwell-time of $1 \mathrm{~s}$ maintained. The additional wavelength regions needed to determine individual line ratios were incorporated in separate campaigns over a number of nights, so that temperature measurements could be maintained. Figure 1 is a compilation of all spectral regions scanned.

Knowledge of the instrument function is needed to allow for contamination by lines not fully separated from adjacent features. A frequency stabilized laser was used to illuminate the entrance aperture and define the instrument function at $\lambda 632.82 \mathrm{~nm}$. This defined the shape of the main passband and the location and magnitude of the first and second Rowland 'ghosts' (Longhurst, 1957). The measured instrument function was scaled to the $\mathrm{OH}(6-2)$ region, maintaining the shape of the main peak and the relative intensity of the ghosts. The displacement of the ghosts from the main peak was scaled in wavelength according to $\Delta \lambda^{\prime} / \lambda^{\prime}=\Delta \lambda / \lambda$.
The full-width-at-half-maximum (fwhm) of the instrument function at the $\mathrm{OH}(6-2) \mathrm{P}_{1}(4)$ wavelength $(\lambda 846.5 \mathrm{~nm})$ was determined by best fitting the sum of two equal instrument functions, separated by the $\mathrm{P}_{1}(4)$ $\Lambda$-doublet separation $(0.0305 \mathrm{~nm})$ to an average measured $\mathrm{P}_{1}(4)$ profile. The $\mathrm{P}_{1}(4)$ line was chosen for this determination in preference to the more intense $P_{1}(2)$ and $\mathrm{P}_{1}(3)$ emissions because of contamination by $\mathrm{Q}_{1}(5)$ and $\mathrm{OH}(5-1) \mathrm{P}_{1}(12)_{e}$ respectively (Greet et al., 1998). The ghosts are assigned a shape similar to that determined for the main peak.

At 100 micron slit separation, a slightly asymmetric, rounded instrument function of fwhm $0.071 \mathrm{~nm}$ is appropriate. The first ghosts are approximately $0.33 \%$ of the main peak, and displaced by $0.354 \mathrm{~nm}$. For the second ghosts, an approximate magnitude of $0.18 \%$ and displacement of $0.71 \mathrm{~nm}$ were estimated. At 250 micron slit separation, an instrument function with a fwhm of $0.155 \mathrm{~nm}$ was similarly determined.

During 1995 and 1996 spectra were collected as continuous scans from $\lambda 837.5 \mathrm{~nm}$ to $\lambda 851.5 \mathrm{~nm}$. The step size was $0.005 \mathrm{~nm}$, the dwell-time was $0.1 \mathrm{~s}$ and the slit widths were 250 microns. Five scans were combined to give a spectrum for temperature analysis. From this data set, 279 spectra obtained during optimal observing conditions and with no significant auroral contamination were chosen. These spectra are principally used to determine two satellite line ratios and to derive average temperatures from $\mathrm{P}_{1}$ line ratio pairs for a comparison of transition probabilities.

A broad classification of sky conditions (clear, thin cirrus, patchy cloud, overcast, snow) was maintained through visual observation and reference to an all-sky video system. The 'thin cirrus' classification describes times when uniform thin high cirrus cloud, through which bright stars are visible, was apparent. In the cold Antarctic winters this is a common condition. Stratospheric haze is also often present, however as it can only be seen in forward scattered sunlight e.g. at twilight, its presence is ignored.

Only spectra that are free of auroral contamination are used in the intensity ratio determinations. In selecting against auroral contamination, reference was

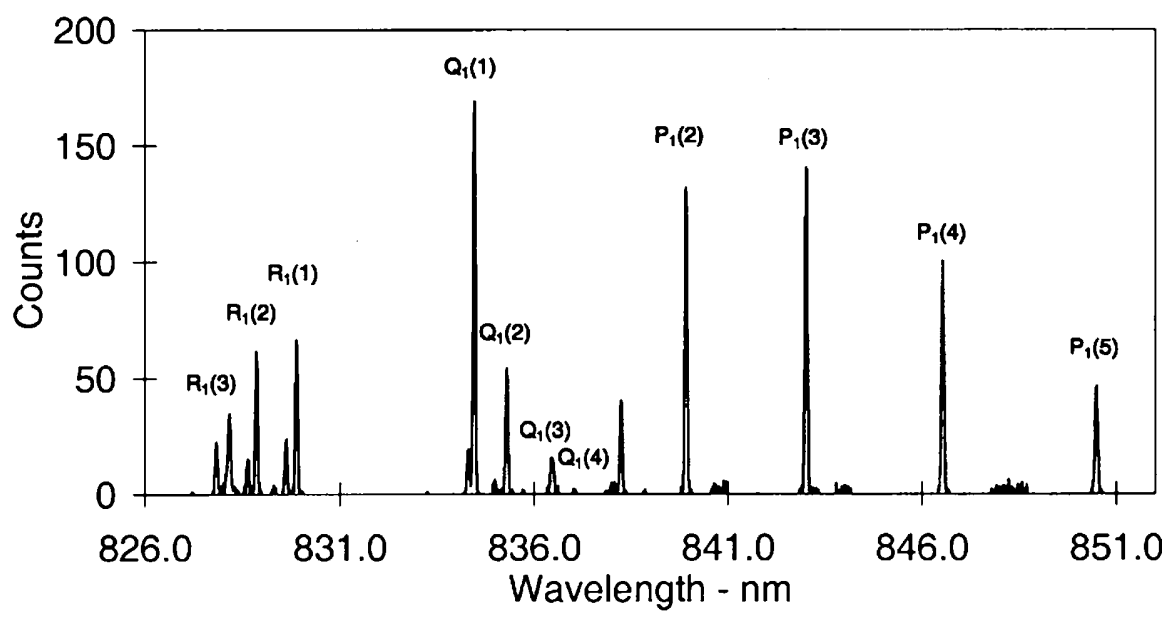

Fig. 1. A compilation of spectral regions scanned with 100 micron slit separations, normalized to 100 counts for the $\mathrm{P}_{1}(4)$ peak intensity. Major lines of interest are labelled. Apparent but not labelled are: $\mathrm{R}_{1}(4+5)$ at $\lambda 827.8 \mathrm{~nm}, \mathrm{R}_{2}(3)$ at $\lambda 828.6 \mathrm{~nm}, \mathrm{R}_{2}(2)$ at $\lambda 829.6 \mathrm{~nm}, \mathrm{Q}_{2}(1)$ at $\lambda 834.3 \mathrm{~nm}, \mathrm{Q}_{2}(2)$ at $\lambda 835.0 \mathrm{~nm}$ and $\mathrm{P}_{2}(2)$ at $\lambda 838.2 \mathrm{~nm}$ 
made to wide-angle (60 degree fov), zenith-oriented photometer measurements of the auroral $\mathrm{N}_{2}^{+} 1 \mathrm{NG}$ band at $\lambda 428 \mathrm{~nm}$.

Meteorological balloon flights, by employees of the Australian Bureau of Meteorology, were conducted twice daily during 1997 at Davis. Measurements taken allow calculation of the equivalent column density of water vapour above the site (Sturman and Tapper, 1996). Reference is made to these data when water absorption of emissions may be significant.

\section{Determination of line ratios}

The desired line intensities are determined after aligning and summing selected spectra. Unless specifically noted, spectra collected with 100 micron slit separations $(0.071 \mathrm{~nm}$ fwhm instrument function) are used. The counts in a $0.125 \mathrm{~nm}$ region centred on the emission of interest are typically determined. The 'count region' occasionally varies, as will be indicated, to allow for difficulties with some emissions. A background level is determined for each emission of interest in the summed files. The fraction of an emission in the count region, and the contamination from nearby emissions, are determined using the instrument function. Allowance is made for $\Lambda$-doubling of the $\mathrm{OH}$ lines. It is assumed that individual $\Lambda$-components are of equal intensity. An estimate of the uncertainty in the derived ratios due to the uncertainty in the 'fitted-to- $\mathrm{P}_{1}(4)$ ' instrument function was obtained by comparison with the results obtained using an instrument function derived by scaling the laser wavelength profile up in wavelength to the $\mathrm{OH}(6-2)$ region. The largest difference in any ratio was $0.2 \%$, an amount insignificant compared with other uncertainties in the measurements.

The only absorber of consequence in the wavelength range covered is $\mathrm{H}_{2} \mathrm{O}$. Using high-resolution telluric absorption spectra (HITRAN92; Rothman et al., 1992) and the technique described in Turnbull and Lowe (1983), the transmission of each $\Lambda$-component has been checked. Where absorption by water vapour may be of concern, it is noted in the specific ratio determinations.
The CZT is a scanning instrument. The $\mathrm{P}_{1}(4)$ emissions in the 1995 and 1996 continuous scans ( 279 spectra) give an average intensity variation of $-0.038 \%$ per minute, consistent with a tendency for decreasing hydroxyl intensity across the night at this site (Greet et al., 1998). The time difference between measuring the line intensities used to determine desired ratios are listed in Table 3. The largest time difference is $7.4 \mathrm{~min}$ [for determining $\mathrm{Q}_{1}(4)$ / $\left.\mathrm{P}_{1}(5)\right]$ and the shortest is $1.2 \mathrm{~min}\left[\mathrm{Q}_{1}(1) / \mathrm{P}_{1}(2)\right]$. For each of the ratios determined, the $\mathrm{P}_{1}(4)$ intensity is monitored, and the average $\mathrm{P}_{1}(4)$ intensity over the summed spectra is calculated as a 'percentage variation per minute'. These values are also listed in Table 3 along with the implied percentage error in the ratio being determined. The greatest uncertainty in the measured ratios, due to the time interval between measuring the individual intensities, is $-0.8 \%$ for the $\mathrm{R}_{1}(3) / \mathrm{P}_{1}(5)$ ratio. No allowance is made for the minor variations possible due to the time interval between measuring the emissions.

The spectral response was determined from 121 separate scans of a calibrated LBS with an average curve suitable for our purposes, as previously indicated in Sect. 3. The standard deviation of the individual scans was used to estimate the uncertainty in the derived ratios due to the spectral response calibration. The uncertainties, no greater than $0.3 \%$ for any ratio, are also listed in Table 3 and are insignificant compared to other sources of error for all ratios.

A range of cloud conditions have been accepted for the ratios determined. A value determined from 'clear sky' spectra is also presented for all ratios except the two satellite line ratios. No statistically significant difference is found between ratios determined under cloudy or clear conditions. In Table 3 are listed the number of spectra summed in determining each ratio and the sky conditions under which those spectra were acquired.

In determining some ratios, it was necessary to include spectra collected when the moon was above the horizon (see Table 3). Separate determination of the background for each emission allows for any spectral slope in moon-affected spectra. A solar spectrum was examined to ensure that Fraunhofer absorption did not affect the ratios determined.
Table 3. Information on the data sets used to derive the indicated ratios. Included are the instrument function fwhm, the time taken to scan between the emissions, the number of spectra in the data set, the sky conditions (cloudy, clear $=\mathrm{clr}$ or thin cirrus $=$ thc), whether the data set includes spectra collected when the moon was above the horizon, the average slope in the $\mathrm{P}_{1}(4)$ intensity for the data set, the error in the ratio implied by the average intensity slope and the spectral response error

\begin{tabular}{|c|c|c|c|c|c|c|c|c|}
\hline Ratio & $\begin{array}{l}\text { fwhm } \\
(\mathrm{nm})\end{array}$ & $\Delta t \min$ & $\begin{array}{l}\text { Number } \\
\text { of spectra }\end{array}$ & Sky & Moon & $\begin{array}{l}\text { Slope variation } \\
\% / \mathrm{min}\end{array}$ & $\begin{array}{l}\text { Scan-time } \\
\text { error } \%\end{array}$ & $\begin{array}{l}\text { Spectral } \\
\text { error } \%\end{array}$ \\
\hline \multirow[t]{2}{*}{$\mathrm{Q}_{1}(1) / \mathrm{P}_{1}(2)$} & 0.071 & 1.2 & 232 & cloudy & No & -0.004 & -0.005 & 0.1 \\
\hline & 0.071 & 1.2 & 6 & $\mathrm{clr}$ & No & 0.18 & 0.2 & 0.1 \\
\hline $\mathrm{Q}_{1}(2) / \mathrm{P}_{1}(3)$ & 0.071 & 3.8 & 74 & $\mathrm{clr}$ & No & -0.05 & -0.2 & 0.2 \\
\hline \multirow[t]{3}{*}{$\mathrm{Q}_{1}(3) / \mathrm{P}_{1}(4)$} & 0.071 & 4.3 & 59 & $\mathrm{clr}+$ the & Yes & -0.07 & -0.3 & 0.2 \\
\hline & 0.071 & 4.3 & 30 & $\mathrm{clr}$ & Yes & 0.04 & 0.2 & 0.2 \\
\hline & 0.155 & 4.0 & 286 & $\mathrm{clr}$ & Yes & 0.02 & 0.06 & 0.2 \\
\hline \multirow[t]{3}{*}{$\mathrm{Q}_{1}(4) / \mathrm{P}_{1}(5)$} & 0.071 & 7.4 & 174 & $\mathrm{clr}+$ the & No & -0.05 & -0.3 & 0.2 \\
\hline & 0.071 & 7.4 & 107 & $\mathrm{clr}$ & No & -0.02 & -0.15 & 0.2 \\
\hline & 0.155 & 6.6 & 279 & $\mathrm{clr}+$ thc & No & -0.04 & -0.25 & 0.2 \\
\hline $\mathrm{R}_{1}(1) / \mathrm{P}_{1}(3)$ & 0.071 & 5.5 & 74 & $\mathrm{clr}$ & No & -0.05 & -0.3 & 0.2 \\
\hline \multirow[t]{2}{*}{$\mathrm{R}_{1}(2) / \mathrm{P}_{1}(4)$} & 0.071 & 4.2 & 46 & $\mathrm{clr}$ & Yes & -0.01 & -0.03 & 0.3 \\
\hline & 0.155 & 3.8 & 69 & $\mathrm{clr}$ & No & -0.03 & -0.1 & 0.3 \\
\hline $\mathrm{R}_{1}(3) / \mathrm{P}_{1}(5)$ & 0.071 & 6.5 & 66 & $\mathrm{clr}$ & No & -0.13 & -0.8 & 0.3 \\
\hline${ }^{\mathrm{Q}_{12}}(1) / \mathrm{P}_{1}(2)$ & 0.155 & 1.9 & 279 & $\mathrm{clr}+$ thc & No & -0.04 & -0.07 & 0.1 \\
\hline${ }^{\mathrm{P}} \mathrm{Q}_{12}(2) / \mathrm{P}_{1}(2)$ & 0.155 & 4.0 & 279 & $\mathrm{clr}+$ the & No & -0.04 & -0.15 & 0.1 \\
\hline
\end{tabular}



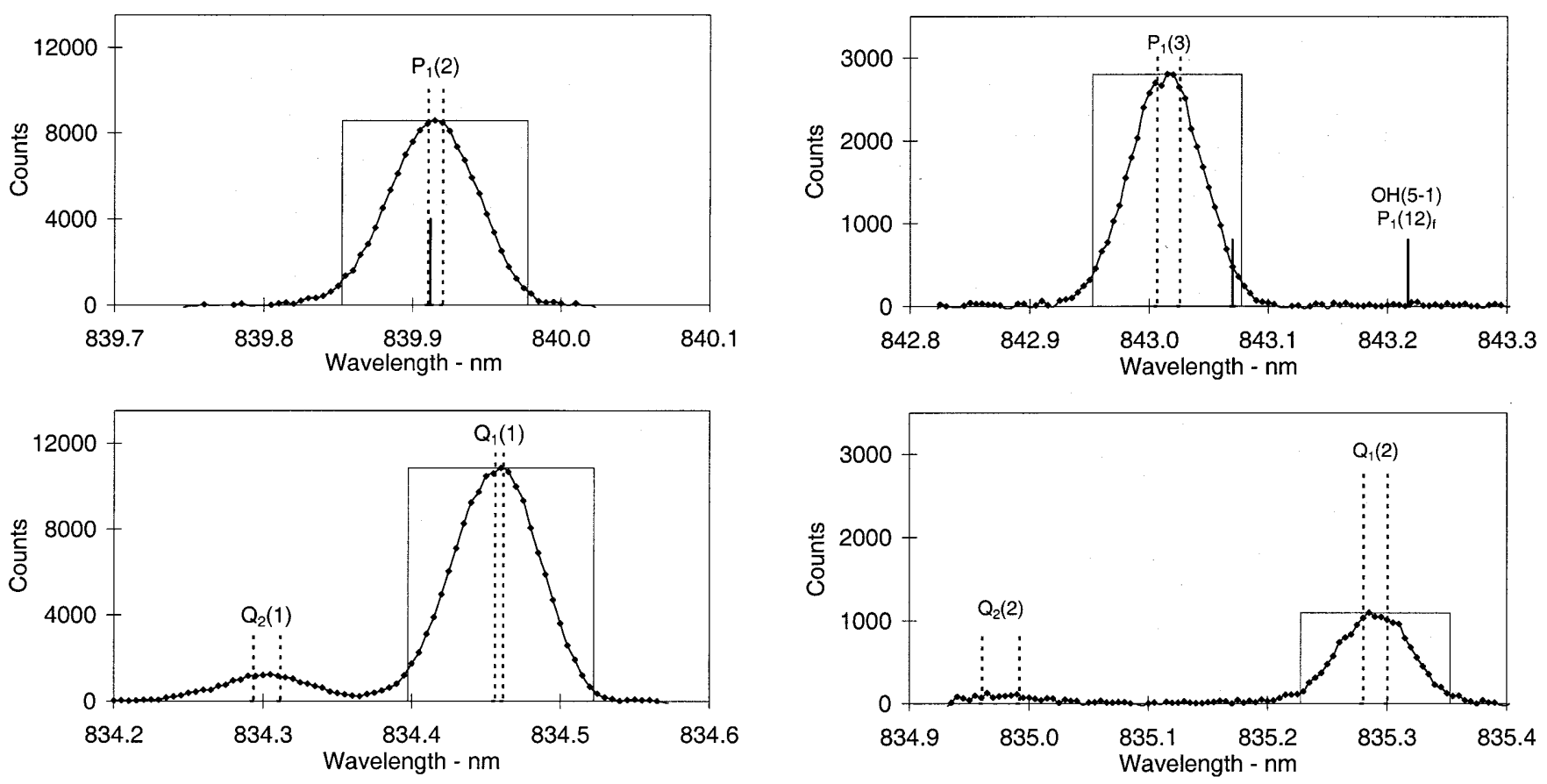

Fig. 2. The 'count regions' for determination of the $\mathrm{Q}_{1}(1) / \mathrm{P}_{1}(2)$ ratio are indicated by rectangles centred on the relevant emissions. The wavelength of the $\mathrm{Q}_{1}(5)_{f}$ line at $\lambda 839.91 \mathrm{~nm}$, which contaminates the $\mathrm{P}_{1}(2)$ emission, is marked but not labelled

An uncertainty is estimated for each ratio as the square-root of the sum of the squares of the relative errors of the individual line intensities. Emission intensity uncertainty includes allowance for counting statistics and uncertainties in estimates of the baseline, contamination by nearby emissions and any atmospheric absorption.

\section{$4.1 Q_{1}(1) / P_{1}(2)\left[j^{\prime}=1.5\right]$}

Two hundred and thirty-two spectra were summed to determine this ratio. All cloud conditions were accepted. Figure 2 shows the $Q_{1}(1)$ and $P_{1}(2)$ regions of the summed spectrum. Only $0.2 \%$ of the $\mathrm{Q}_{2}(1)$ emission falls in the $\mathrm{Q}_{1}(1)$ count region. Ninety-six percent of the $\mathrm{Q}_{1}(5)_{f}$ line and $1.3 \%$ of the $\mathrm{Q}_{1}(5)_{e}$ line (at $\lambda 840.04 \mathrm{~nm}$ ) lie in the $\mathrm{P}_{1}(2)$ count region. For a temperature of $200 \mathrm{~K}$, the estimates of the total intensity of the $\mathrm{Q}_{1}(5)$ emission with respect to the $\mathrm{P}_{1}(2)$ emission for Mies, LWR and T\&L transition probabilities varies between $1.6-1.7 \%$. The range for a temperature of $240 \mathrm{~K}$ is $2.7-$ $2.9 \%$. A reasonable estimate of the $\mathrm{Q}_{1}(5)$ intensity relative to the $P_{1}(2)$ intensity for winter temperatures above Davis is $2.2 \pm 0.8 \%$. Taking $\mathrm{Q}_{1}(5)$ contamination of this level into account, the $\mathrm{Q}_{1}(1) / \mathrm{P}_{1}(2)$ ratio is measured to be $1.261 \pm 0.012$. This is the only ratio determined without any selection against cloud conditions. There were only six spectra collected under clear skies. These six spectra when combined yield a $\mathrm{Q}_{1}(1) /$ $\mathrm{P}_{1}(2)$ ratio of $1.31 \pm 0.07$. Variations in intensity in the $1.2 \mathrm{~min}$ between measuring the two emissions, determined from variations in the $\mathrm{P}_{1}(4)$ intensity, average out

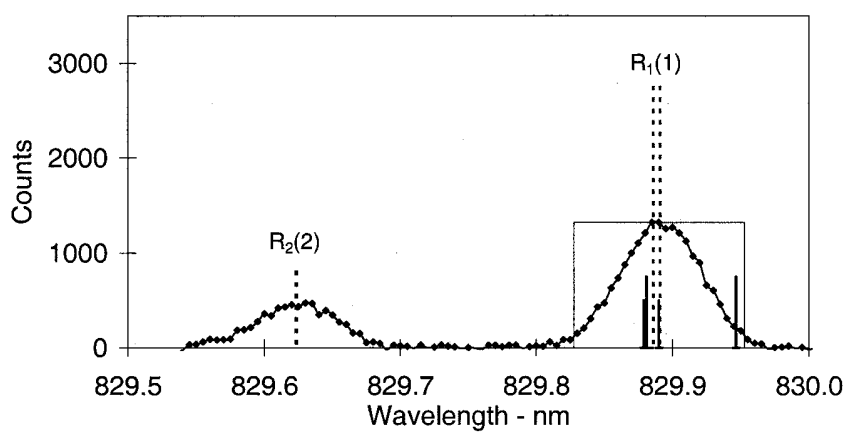

Fig. 3. Spectral regions for evaluation of the $\mathrm{Q}_{1}(2) / \mathrm{P}_{1}(3)$ and $\mathrm{R}_{1}(1) /$ $\mathrm{P}_{1}(3)$ ratios. The locations of the contaminating lines, ${ }^{\mathrm{Q}} \mathrm{P}_{21}(3)_{e}$ at $\lambda 829.88 \mathrm{~nm}, \mathrm{OH}(5-1) \mathrm{P}_{2}(10)_{f}$ at $\lambda 829.88 \mathrm{~nm},{ }^{\mathrm{Q}} \mathrm{P}_{21}(3)_{f}$ at $\lambda 829.89 \mathrm{~nm}$, $\mathrm{OH}(5-1) \mathrm{P}_{2}(10)_{e}$ at $\lambda 829.95 \mathrm{~nm}$ and $\mathrm{OH}(5-1) \mathrm{P}_{1}(12)_{e}$ at $\lambda 843.07 \mathrm{~nm}$, are marked without label

to be insignificant $(-0.005 \%$, see Table 3$)$. Dominant sources of uncertainty come from estimations of the $\mathrm{P}_{1}(2)$ background and the $\mathrm{Q}_{1}(5)$ contamination.

\section{$4.2 R_{1}(1) / P_{1}(3)$ and $Q_{1}(2) / P_{1}(3)\left[j^{\prime}=2.5\right]$}

Seventy-four spectra were summed to determine the $\mathrm{R}_{1}(1) / \mathrm{P}_{1}(3)$ and $\mathrm{Q}_{1}(2) / \mathrm{P}_{1}(3)$ ratios. Figure 3 shows the $\mathrm{R}_{1}(1), \mathrm{Q}_{1}(2)$ and $\mathrm{P}_{1}(3)$ regions of the summed spectra. An estimated $61 \%$ of the unthermalized $\mathrm{OH}(5-1)$ $\mathrm{P}_{1}(12)_{e}$ line lies in the $\mathrm{P}_{1}(3)$ count region. The $\mathrm{OH}(5-1) \mathrm{P}_{1}(12)_{f}$ line is centred, $0.2 \mathrm{~nm}$ towards longer wavelengths from the peak of the $\mathrm{P}_{1}(3)$ emission. From the summed spectrum, it is estimated that the $\mathrm{OH}(5-1)$ $\mathrm{P}_{1}(12)_{f}$ line is $1.0 \pm 0.6 \%$ of the $\mathrm{P}_{1}(3)$ intensity. This is lower than, but within estimated uncertainties, the value determined by Greet et al. (1998).

Ninety-five percent of the $\mathrm{OH}(5-1) \mathrm{P}_{2}(10)_{f}$ line and $55 \%$ of the $\mathrm{P}_{2}(10)_{e}$ line lie in the $\mathrm{R}_{1}(1)$ count region. We 
assume that the intensities of these unthermalized lines are equal to the measured $\mathrm{OH}(5-1) \mathrm{P}_{1}(12)_{f}$ intensity. An uncertainty amounting to $60 \%$ of the estimated contamination is ascribed. Ninety-five percent of the $\mathrm{OH}$ (6-2) satellite line ${ }^{{ }^{2}} P_{21}(3)$ also lies in the $R_{1}(1)$ count region. Goldman (1982) gives transition probabilities for the satellite lines consistent with Mies values for the major lines. For a temperature range of $200 \mathrm{~K}$ to $240 \mathrm{~K}$, these transition probabilities yield ${ }^{{ }^{Q}} P_{21}(3) / R_{1}(1)$ ratios ranging from $0.95 \%$ to $1.25 \%$. A ratio of $1.1 \%$ is used to estimate the ${ }^{{ }^{2}} \mathrm{P}_{21}(3)$ contamination. We assign an uncertainty estimated as half the contamination value. The $R_{1}(1) / P_{1}(3)$ ratio is measured to be $0.436 \pm 0.016$. The principal uncertainty results from estimations of the contamination of the $\mathrm{R}_{1}(1)$ measurement.

The $\mathrm{Q}_{1}(2) / \mathrm{P}_{1}(3)$ ratio is measured to be $0.389 \pm 0.006$. The main sources of uncertainty are in the determination of the baseline for the $\mathrm{Q}_{1}(2)$ line and in estimating the $\mathrm{OH}(5-1) \mathrm{P}_{1}(12)_{e}$ contamination of the $\mathrm{P}_{1}(3)$ intensity.

\section{$4.3 R_{1}(2) / P_{1}(4)\left[j^{\prime}=3.5\right]$}

Forty-six spectra were summed for determination of the $\mathrm{R}_{1}(2) / \mathrm{P}_{1}(4)$ ratio. Figure 4 shows the $\mathrm{R}_{1}(2)$ and $\mathrm{P}_{1}(4)$ regions of the summed spectrum. $\mathrm{OH}(9-4) \mathrm{P}_{1}(12)_{f}$ is blended with $\mathrm{R}_{1}(2)$, but $\mathrm{OH}(9-4) \mathrm{P}_{1}(12)_{e}$ at $\lambda 828.725 \mathrm{~nm}$ is not discernible (see Fig. 4), therefore no allowance is made for this contaminant. Water vapour is potentially an absorber of the $\mathrm{R}_{1}(2)$ emission, but the atmosphere above Davis in winter is very dry. Meteorological balloon flights at Davis station on the days these spectra were collected yield a water vapour column density of
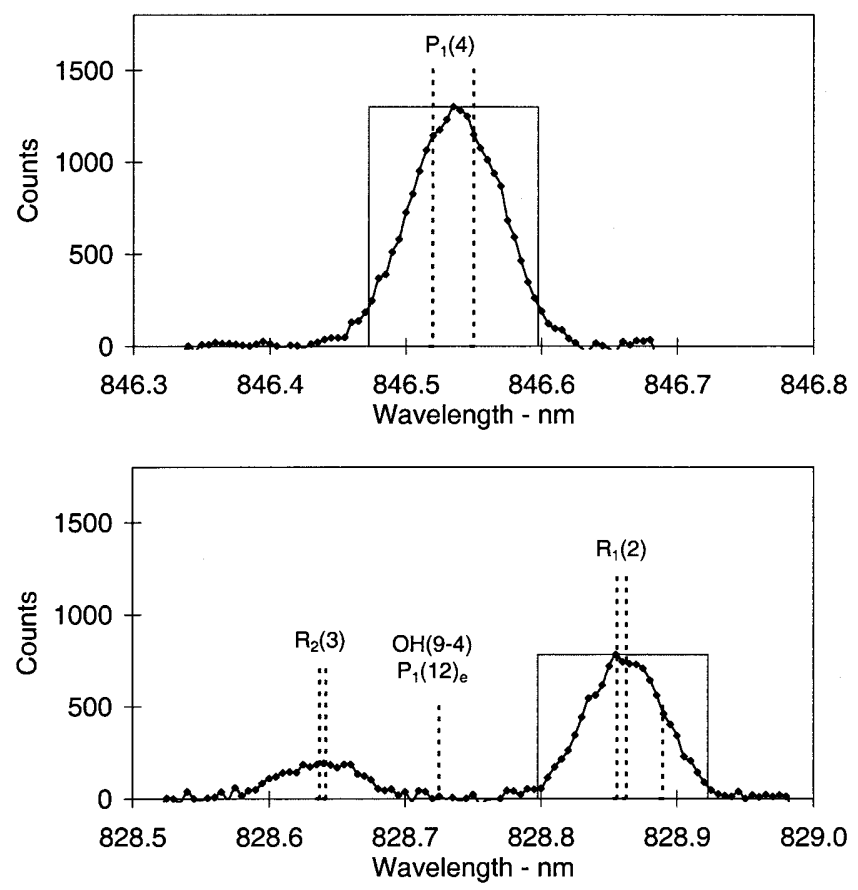

Fig. 4. Summed spectral profiles showing the $R_{1}(2)$ and $P_{1}(4)$ spectral regions. $\mathrm{OH}(9-4) \mathrm{P}_{1}(12)_{f}$ at $\lambda 828.89 \mathrm{~nm}$ is marked without label
$1.8 \pm 1 \mathrm{~mm} \mathrm{~cm}^{-2}$. This implies only a $0.23 \%$ absorption of the $\mathrm{R}_{1}(2)$ emission. An $\mathrm{R}_{1}(2) / \mathrm{P}_{1}(4)$ ratio of $0.514 \pm 0.013$ is obtained from these spectra.

Sixty-nine spectra collected with 250 micron slit separations were also summed to obtain an independent estimation of this ratio. Count regions $0.25 \mathrm{~nm}$ wide centred on the respective emissions were selected. With this wider instrument function, it was necessary to allow for $6 \%$ of $\mathrm{R}_{2}(3)$ under the $\mathrm{R}_{1}(2)$ count region. Water vapour content was measured to be $3.5 \pm 1.5 \mathrm{~mm}$ $\mathrm{cm}^{-2}$, implying a $0.45 \% \mathrm{R}_{1}(2)$ absorption. An $\mathrm{R}_{1}(2) /$ $\mathrm{P}_{1}(4)$ ratio of $0.510 \pm 0.009$ is measured. The larger number of suitable spectra, and the higher intensities obtained with the larger slit separations, yield a more accurate determination of the ratio. The principal source of uncertainty in both determinations comes from the background estimate for the $\mathrm{R}_{1}(2)$ region.

\section{$4.4 Q_{1}(3) / P_{1}(4)\left[j^{\prime}=3.5\right]$}

Fifty-nine spectra were summed to measure the $\mathrm{Q}_{1}(3) /$ $\mathrm{P}_{1}(4)$ ratio. Seventy-two percent of the $\mathrm{OH}(5-1) \mathrm{P}_{1}(11)_{e}$ emission lies in the $\mathrm{Q}_{1}(3)$ count region. To obtain some estimate of the contribution of this feature, we assume it is of the same average relative magnitude as $\mathrm{OH}(5-1)$ $\mathrm{P}_{1}(12)_{f}$ which was measured in Sect. 4.2. Assuming an $\mathrm{OH}$ temperature of $220 \mathrm{~K}$, the $\mathrm{OH}(5-1) \mathrm{P}_{1}(11)_{e}$ emission amounts to $1.3 \%$ of the $\mathrm{P}_{1}(4)$ intensity. The implied correction to the counts under the $\mathrm{Q}_{1}(3)$ summing region is $5.5 \%$. The $\mathrm{Q}_{1}(3) / \mathrm{P}_{1}(4)$ ratio is measured to be $0.179 \pm 0.012$. For the 30 'clear-sky' spectra in this data set, the $\mathrm{Q}_{1}(3) / \mathrm{P}_{1}(4)$ ratio was $0.176 \pm 0.017$. The principal sources of error come from estimation of the
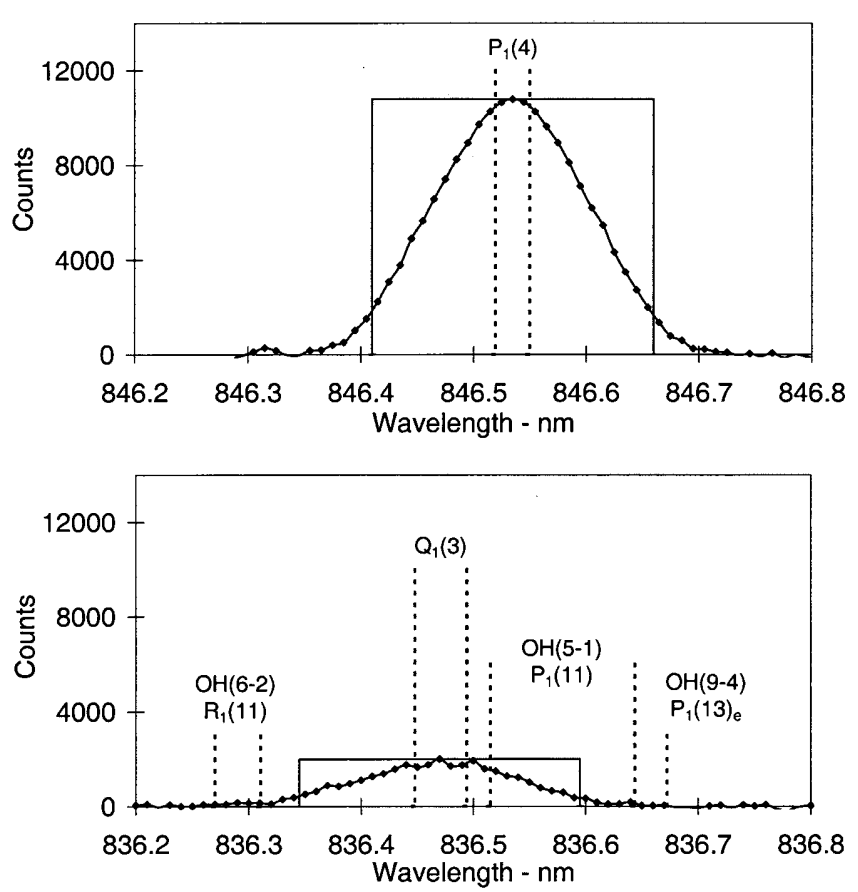

Fig. 5. Summed profiles in the regions of $Q_{1}(3)$ and $P_{1}(4)$ obtained with a $0.155 \mathrm{~nm}$ instrument function 
$\mathrm{OH}(5-1) \mathrm{P}_{1}(11)$ contamination and the low intensity of the $\mathrm{Q}_{1}(3)$ emission.

Two hundred and eighty-six files acquired with 250 micron slit widths were summed to obtain an independent estimation of the $\mathrm{Q}_{1}(3) / \mathrm{P}_{1}(4)$ ratio. Count regions $0.25 \mathrm{~nm}$ wide centred on the respective emissions were used. Figure 5 shows the $\mathrm{Q}_{1}(3)$ and $\mathrm{P}_{1}(4)$ regions of the summed spectrum. Potential contaminants of the $\mathrm{Q}_{1}(3)$ emission, measured with this larger instrument function, are $\mathrm{OH}(5-1) \quad \mathrm{P}_{1}(11), \mathrm{OH}(6-2) \quad \mathrm{R}_{1}(11)$ and $\mathrm{OH}(9-4)$ $\mathrm{P}_{1}(13)_{e}$. The $\mathrm{OH}(9-4) \mathrm{P}_{1}(13)_{e}$ and $\mathrm{OH}(6-2) \mathrm{R}_{1}(11)$ contaminations are insignificant with respect to the uncertainty in the background level. The $\mathrm{OH}(5-1)$ $\mathrm{P}_{1}(11)_{e}$ line remains the principal contaminant, with $89 \%$ of its total intensity in the $\mathrm{Q}_{1}(3)$ count region. Twenty-three percent of the $\mathrm{OH}(5-1) \mathrm{P}_{1}(11)_{f}$ intensity also contaminates $\mathrm{Q}_{1}(3)$. By assuming each is equivalent in average intensity to the measurement made of the $\mathrm{OH}(5-1) \mathrm{P}_{1}(12)_{f}$ line, $7.7 \%$ of the counts in the $\mathrm{Q}_{1}(3)$ count region are estimated to result from the $\mathrm{OH}(5-1)$ $\mathrm{P}_{1}(11)$ emission. The $\mathrm{Q}_{1}(3) / \mathrm{P}_{1}(4)$ ratio is thus $0.168 \pm 0.011$. The principal uncertainty is in estimation of the $\mathrm{OH}(5-1) \mathrm{P}_{1}(11)$ contamination.

The similarity of the uncertainties associated with the $\mathrm{Q}_{1}(3) / \mathrm{P}_{1}(4)$ determinations imply an average value, $0.173 \pm 0.011$, is appropriate. We have not reduced the uncertainty, due to its strong dependence on the method used to estimate the $\mathrm{OH}(5-1)$ contamination.

\section{$4.5 R_{1}(3) / P_{1}(5)\left[j^{\prime}=4.5\right]$}

Sixty-six spectra were summed to determine the $\mathrm{R}_{1}(3) /$ $P_{1}(5)$ ratio. Figure 6 shows the $R_{1}(3)$ and $P_{1}(5)$ regions of the summed spectrum. The $R_{1}(3)$ region is very
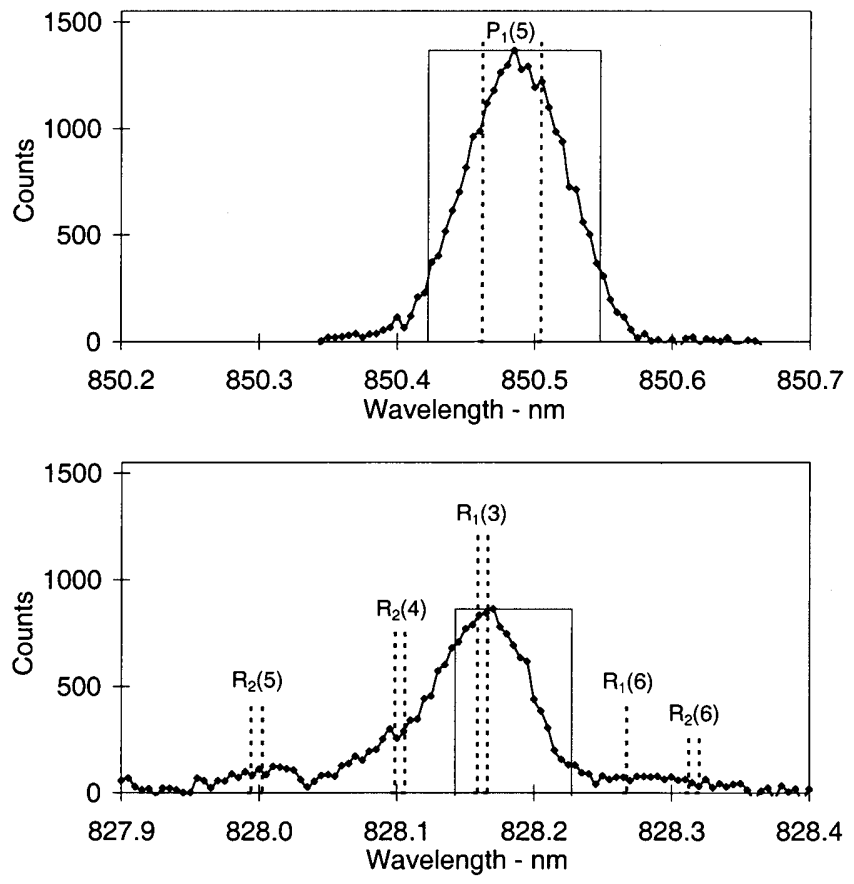

Fig. 6. Summed profiles of the $\mathrm{R}_{1}(3)$ and $\mathrm{P}_{1}(5)$ spectral regions. The $\mathrm{R}_{1}(6) \Lambda$-components are sufficiently close to be indistinguishable crowded. An additional difficulty is that $\mathrm{R}_{1}(3)$ may be significantly absorbed by atmospheric water vapour. The water column density over Davis when these spectra were acquired was measured to be $1.5 \pm 1 \mathrm{~mm} \mathrm{~cm}^{-2}$. For this level of atmospheric water vapour, the $\mathrm{R}_{1}(3)_{f}$ line at $828.164 \mathrm{~nm}$ is $0.45 \%$ absorbed and the $\mathrm{R}_{1}(3)_{e}$ component at $828.171 \mathrm{~nm}$ is $0.7 \%$ absorbed.

The $R_{1}(3)$ emission is significantly contaminated on the low wavelength side by $\mathrm{R}_{2}(4)$. Some allowance is made for this contamination by using an asymmetric $\mathrm{R}_{1}(3)$ count region, from $0.0225 \mathrm{~nm}$ below the $\mathrm{R}_{1}(3)$ centre wavelength to $0.0625 \mathrm{~nm}$ above. This reduces the $\mathrm{R}_{2}(4)$ contamination of the $\mathrm{R}_{1}(3)$ count region to $6.8 \%$ of the total $R_{2}(4)$ intensity. The $R_{2}(4)$ intensity is estimated by counting from the $\mathrm{R}_{2}(4)$ centre wavelength, $0.0625 \mathrm{~nm}$ towards lower wavelengths. Ten percent of the total $R_{1}(6)$ intensity lies within the $R_{1}(3)$ count region. The $R_{1}(6)$ intensity is estimated using a count region from its centre wavelength, $0.0625 \mathrm{~nm}$ towards higher wavelengths. The $R_{1}(3) / P_{1}(5)$ ratio is measured as $0.483 \pm 0.017$. Uncertainties in the estimation of the $\mathrm{R}_{1}(3)$ contaminants are the principal source of error.

$4.6 Q_{1}(4) / P_{1}(5)\left[j^{\prime}=4.5\right]$

One hundred and seventy-four spectra were summed to determine a $\mathrm{Q}_{1}(4) / \mathrm{P}_{1}(5)$ ratio of $0.107 \pm 0.009$. The principal source of error is the low intensity of the $Q_{1}(4)$ emission.

The two hundred and seventy-nine spectra from 1995 and 1996 were used to independently determine the $\mathrm{Q}_{1}(4) / \mathrm{P}_{1}(5)$ ratio. Figure 7 shows the $\mathrm{Q}_{1}(4)$ and $\mathrm{P}_{1}(5)$
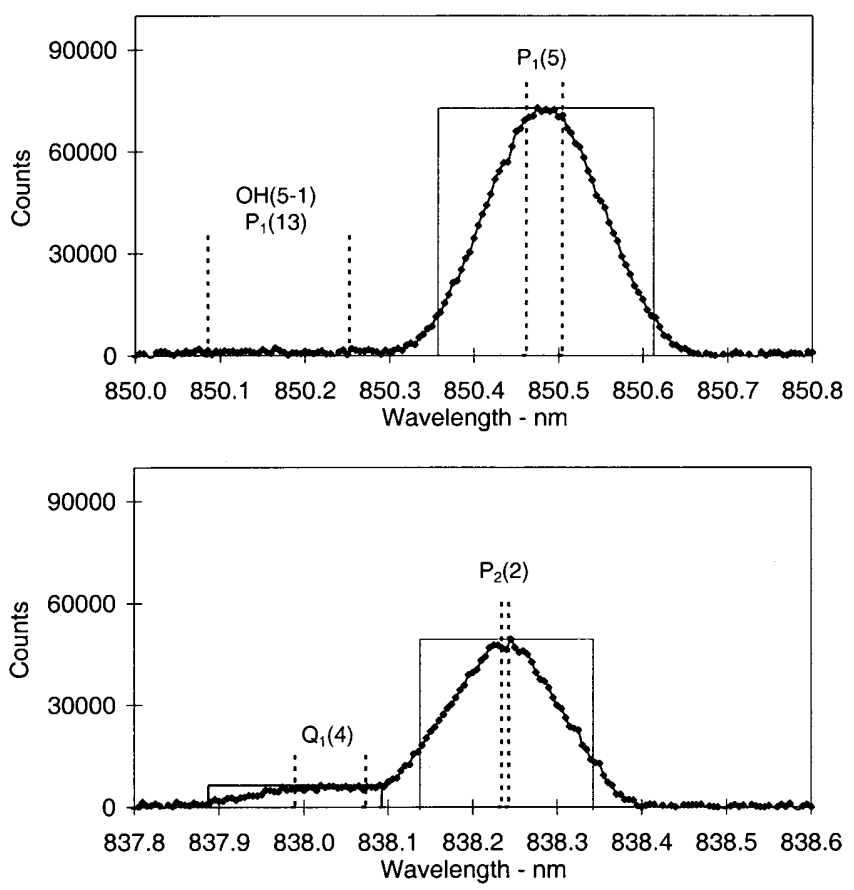

Fig. 7. Summed profiles of the $\mathrm{Q}_{1}(4)$ and $\mathrm{P}_{1}(5)$ regions obtained with a $0.155 \mathrm{~nm}$ instrument function. The respective count regions are indicated by rectangles. The asymmetric count region chosen for the $\mathrm{Q}_{1}(4)$ measurement is apparent 
spectral regions of the summed file. The larger instrument function leads to an overlap of the $\mathrm{P}_{2}(2)$ emission with the less intense $Q_{1}(4)$ emission. This is partially compensated by defining an asymmetric $Q_{1}(4)$ count region, from $0.1425 \mathrm{~nm}$ below the $\mathrm{Q}_{1}(4)$ central wavelength to $0.0625 \mathrm{~nm}$ above (see Fig. 7). Less than $0.8 \%$ of the $\mathrm{P}_{2}(2)$ emission contaminates this $\mathrm{Q}_{1}(4)$ count region. $\mathrm{A}_{1}(4) / \mathrm{P}_{1}(5)$ ratio of $0.094 \pm 0.004$ is determined. The uncertainty estimate is lower than for the 100 micron spectra due to increased $Q_{1}(4)$ photon counts. We use this more reliable estimate of the $\mathrm{Q}_{1}(4) /$ $\mathrm{P}_{1}(5)$ ratio in further evaluations.

\subsection{Satellite line ratios: ${ }^{P} Q_{12}(2) / P_{1}(2)$ and ${ }^{Q} R_{12}(1) / P_{1}(2)\left[j^{\prime}=1.5\right]$}

The 279 spectra from 1995 and 1996 were used to estimate the ratios of two of the $\mathrm{OH}(6-2)$ satellite lines. Figure 8
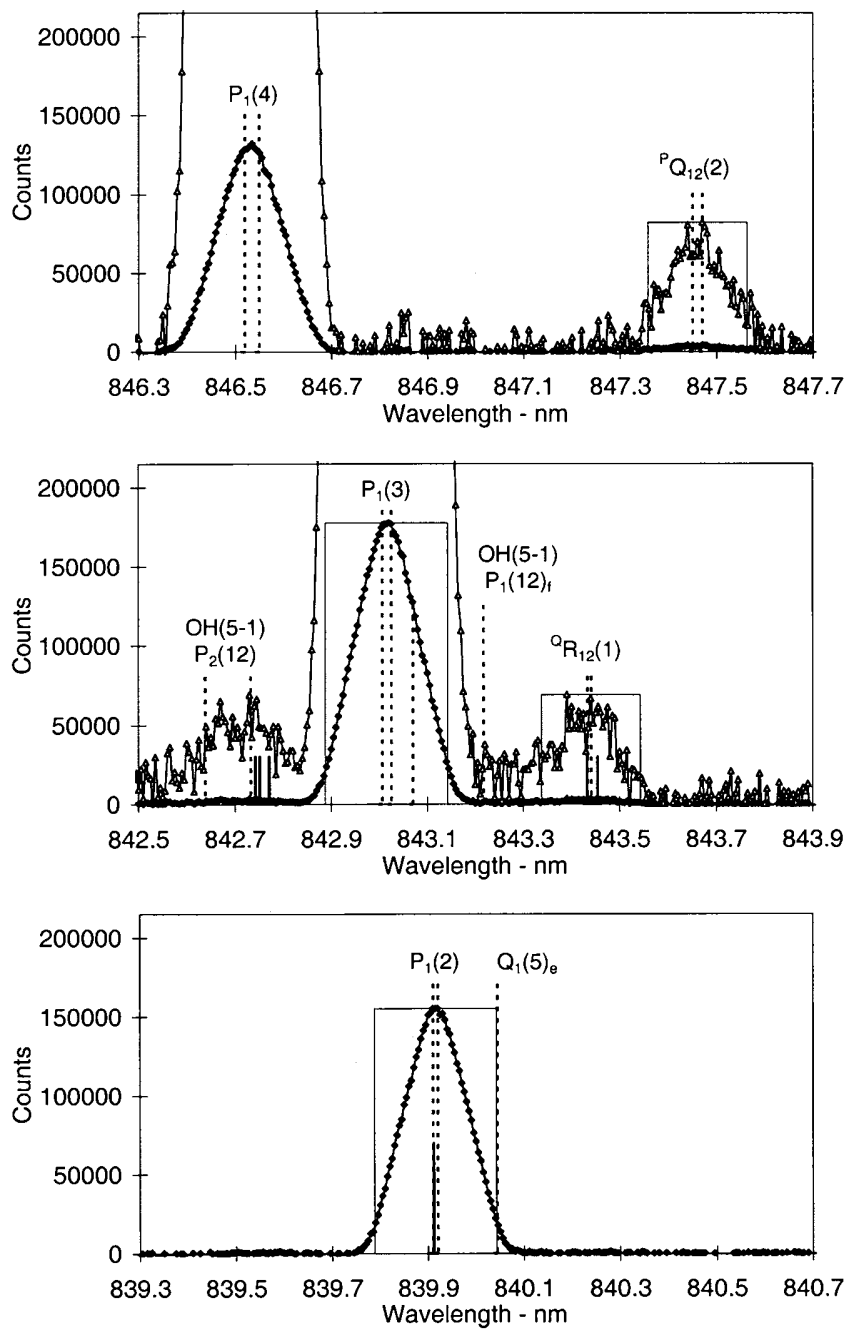

Fig. 8. Summed profiles of the $\mathrm{P}_{1}(2),{ }^{\mathrm{Q}} \mathrm{R}_{12}(1)$ and ${ }^{\mathrm{P}} \mathrm{Q}_{12}(2)$ regions obtained with a $0.155 \mathrm{~nm}$ instrument function. The ${ }^{\mathrm{Q}} \mathrm{R}_{12}(1)$ and ${ }^{\mathrm{P}} \mathrm{Q}_{12}(2)$ regions are also shown at 20 times enhancement to enhance the less intense emissions. The locations of the lines: $\mathrm{Q}_{1}(5)_{f}$ at $\lambda 839.91 \mathrm{~nm},{ }^{\mathrm{Q}} \mathrm{R}_{12}(2)$ at $\lambda 842.74 \mathrm{~nm}$ and $\lambda 842.75 \mathrm{~nm},{ }^{\mathrm{Q}} \mathrm{R}_{12}(3)$ at $\lambda 842.77 \mathrm{~nm}, \mathrm{OH}(5-1) \mathrm{P}_{1}(12)_{e}$ at $\lambda 843.07 \mathrm{~nm}$, and ${ }^{\mathrm{Q}_{\mathrm{R}}} \mathrm{R}_{12}(4)$ at $\lambda 843.43 \mathrm{~nm}$ and $\lambda 843.45 \mathrm{~nm}$ are marked without label shows the $\mathrm{P}_{1}(2),{ }^{\mathrm{Q}} \mathrm{R}_{12}(1)$ [near $\mathrm{P}_{1}(3)$ ] and ${ }^{\mathrm{P}} \mathrm{Q}_{12}(2)$ [near $\left.\mathrm{P}_{1}(4)\right]$ regions of the summed spectrum. Also shown are the ${ }^{\mathrm{Q}} \mathrm{R}_{12}(1)$ and ${ }^{\mathrm{P}} \mathrm{Q}_{12}(2)$ regions at 20 times magnification, so as to better display the satellite lines.

The ${ }^{\mathrm{P}} \mathrm{Q}_{12}(2)$ intensity is estimated from a centred count region, $0.205 \mathrm{~nm}$ wide, and the $\mathrm{P}_{1}(2)$ intensity is measured using a centred count region, $0.255 \mathrm{~nm}$ wide. The $\mathrm{P}_{1}(2)$ count region is contaminated by $72.5 \%$ of the $\mathrm{Q}_{1}(5)$ emission. The $\mathrm{Q}_{1}(5)$ intensity is estimated to be $2.2 \pm 0.8 \%$ of the $\mathrm{P}_{1}(2)$ intensity, as per Sect. 4.1. A ${ }^{\mathrm{P}} \mathrm{Q}_{12}(2) / \mathrm{P}_{1}(2)$ ratio of $0.022 \pm 0.001$ is determined. This is significantly larger than the theoretical value of 0.018 determined from Goldman (1982). We have conservatively estimated the uncertainties possible from all known contaminants to the measured ratios, but if unknown contaminants exist their possible impact would be greatest on the lowest intensity features measured, such as the satellite lines.

The ${ }^{\mathrm{Q}} \mathrm{R}_{12}(1)$ emission has a number of contaminants. A count region $0.205 \mathrm{~nm}$ wide, centred on the ${ }^{\mathrm{Q}} \mathrm{R}_{12}(1)$ emission was used. Contamination from the $\mathrm{OH}(5-1)$ $\mathrm{P}_{1}(12) \Lambda$-components is relatively minor, with $1.2 \%$ of the $\mathrm{OH}(5-1) \mathrm{P}_{1}(12)$ intensity contaminating the ${ }^{\mathrm{Q}} \mathrm{R}_{12}(1)$ count region. As in Sect. 4.2, $\mathrm{OH}(5-1) \mathrm{P}_{1}(12)_{f}$ was estimated as $1.0 \pm 0.6 \%$ of the total $P_{1}(3)$ intensity. More significantly, the first ghost of $\mathrm{P}_{1}(3)$ contaminates the $\mathrm{Q}_{12}(1)$ count region. This contamination amounts to $0.23 \%$ of the $\mathrm{P}_{1}(3)$ intensity. The ${ }^{\mathrm{Q}} \mathrm{R}_{12}(1)$ line is blended with ${ }^{\mathrm{Q}_{12}} \mathrm{R}_{12}$ ) (see Fig. 8). Goldman's (1982) transition probabilities give the ${ }^{\mathrm{Q}} \mathrm{R}_{12}(4)$ intensity as $2.3 \%$ of ${ }^{\mathrm{Q}} \mathrm{R}_{12}(1)$ at $200 \mathrm{~K}$ and $3.1 \%$ at $240 \mathrm{~K}$. A value of $2.7 \%$ was used to estimate the ${ }^{\mathrm{Q}} \mathrm{R}_{12}$ (4) contamination. In total, $22 \%$ of the ${ }^{\mathrm{Q}} \mathrm{R}_{12}(1)$ count region is estimated to come from contaminants. A ${ }^{2} R_{12}(1) / P_{1}(2)$ ratio of $0.014 \pm 0.002$ is determined. This is not significantly different from the Goldman (1982) theoretical value of 0.015 . Estimating the contamination of the ${ }^{2} R_{12}(1)$ count region is the greatest source of error, with the $\mathrm{P}_{1}(3)$ ghost being the most significant contaminant.

\subsection{Comparison with published line ratios}

Table 1 lists the line ratios calculated from the published transition probabilities of T\&L, Mies and LWR, and the experimentally determined values. Experimental $\mathrm{Q}_{1} / \mathrm{P}_{1}$ ratios form a sequence significantly lower than any of the theoretical values, but closest to LWR values. Measured $\mathrm{R}_{1} / \mathrm{P}_{1}$ ratios are not significantly different from the LWR values, but significantly lower than those derived from $\mathrm{T} \& \mathrm{~L}$ and Mies. The measured ${ }^{\mathrm{Q}} \mathrm{R}_{12}(1) / \mathrm{P}_{1}(2)$ ratio of $0.014 \pm 0.002$ is not significantly different from the Goldman (1982) value, while the ${ }^{\mathrm{P}} \mathrm{Q}_{12}(2) / \mathrm{P}_{1}(2)$ value of $0.022 \pm 0.001$ is significantly higher. Table 2 lists the satellite line ratios calculated from Goldman (1982).

\section{Comparison of temperature determinations}

To derive a temperature from an $\mathrm{OH}(6-2)$ spectrum it is necessary to know the relative splitting of the upper 
Table 4. The relative $j^{\prime}$-component sums of the of $\mathrm{P}_{1}, \mathrm{Q}_{1}$ and $\mathrm{R}_{1}$ branch transition probabilities across the (6-2) band for T\&L, Mies and LWR. Also shown are the relative sums determined by including the satellite lines from Goldman (1982). Each ratio is set to 1 for $j^{\prime}=1.5$

\begin{tabular}{|c|c|c|c|c|c|c|}
\hline \multirow[t]{2}{*}{$j^{\prime}$} & \multicolumn{2}{|l|}{$\mathrm{T} \& \mathrm{~L}$} & \multicolumn{2}{|l|}{ Mies } & \multicolumn{2}{|l|}{ LWR } \\
\hline & $\mathrm{P}_{1} \mathrm{Q}_{1} \mathrm{R}_{1}$ & $\begin{array}{l}\text { Including } \\
\text { satellite }\end{array}$ & $\mathrm{P}_{1} \mathrm{Q}_{1} \mathrm{R}_{1}$ & $\begin{array}{l}\text { Including } \\
\text { satellite }\end{array}$ & $\mathrm{P}_{1} \mathrm{Q}_{1} \mathrm{R}_{1}$ & $\begin{array}{l}\text { Including } \\
\text { satellite }\end{array}$ \\
\hline 1.5 & 1.000 & 1.000 & 1.000 & 1.000 & 1.000 & 1.000 \\
\hline 2.5 & 1.000 & 0.997 & 1.002 & 0.999 & 1.004 & 1.002 \\
\hline 3.5 & 0.998 & 0.992 & 1.002 & 0.997 & 1.003 & 0.998 \\
\hline 4.5 & 0.993 & 0.990 & 1.002 & 0.994 & 1.001 & 0.999 \\
\hline 5.5 & 0.986 & 0.977 & 0.999 & 0.990 & 0.996 & 0.987 \\
\hline
\end{tabular}

states of the emissions considered. The $\mathrm{OH}$ molecule is known to exhibit strong coupling of rotational and vibrational components (see e.g., Mies). If the relative proportions of the upper state that decay via the $\mathrm{P}, \mathrm{Q}$ and $\mathrm{R}$ branches differ depending on the $\Delta v$ of the band, then the temperature independent ratios across all bands from the same vibrational upper state need to be measured before the relative splitting needed to determine hydroxyl rotation temperatures can be derived. However, the strongest departure from branch balance between bands is exhibited by the weak $\Delta v=1$ transitions. Table 4 lists the relative $j^{\prime}$-component sums of the of $\mathrm{P}_{1}, \mathrm{Q}_{1}$ and $\mathrm{R}_{1}$ branch transition probabilities across the (6-2) band for T\&L, Mies and LWR. The variation between the upper states is less than $1 \%$, up to $j^{\prime}=4.5$. A $1 \%$ error in the $\mathrm{OH}(6-2) \mathrm{P}_{1}(2) / \mathrm{P}_{1}(5)$ ratio corresponds to a $1 \mathrm{~K}$ error in the derived temperature. $\mathrm{T} \& \mathrm{~L}$, Mies and LWR do not list transition probabilities for the weak satellite lines, but if we incorporate Goldman (1982) values for the satellite lines as a proportion of the $\mathrm{P}_{1}$-branch transition (see also Table 4), the disparity up to $j^{\prime}=4.5$ remains less than $1 \%$. It is thus reasonable to estimate the relative proportions of the upper state that decay via the various branches within the (6-2) band as a percentage of the transitions within that band.

It has not been possible to measure all the ratios required up to the desired level of $j^{\prime}=4.5$, but those missing are mainly low-intensity satellite lines. The measurements that have been made can be extrapolated to estimate the ratios required, or the best available theoretical estimates can be used to supplement the experimental measurements. The ${ }^{\mathrm{Q}} \mathrm{R}_{12}(1) / \mathrm{P}_{1}(2)$ ratio measured was equal to the Goldman (1982) theoretical value. No measured estimates of ${ }^{O} \mathrm{P}_{12} / \mathrm{P}_{1}$ ratios are available. Thus, for the required ${ }^{\mathrm{Q}} \mathrm{R}_{12} / \mathrm{P}_{1}$ and ${ }^{\mathrm{O}} \mathrm{P}_{12} / \mathrm{P}_{1}$ ratios, the values of Goldman (1982) are used. For the ${ }^{\mathrm{P}} \mathrm{Q}_{12} / \mathrm{P}_{1}$ ratios, the measured value is used for ${ }^{\mathrm{P}} \mathrm{Q}_{12}(2) /$ $\mathrm{P}_{1}(2)\left[j^{\prime}=1.5\right]$ and the other required values are scaled proportionally. An uncertainty of half the estimated intensity is used for satellite lines for which no direct measurement is available. In this manner we can derive the fraction of the upper state that decays via each transition, up to $j^{\prime}=4.5$. To make an allowance for $\mathrm{Q}_{1}(5)$ which is blended with the $\mathrm{P}_{1}(2)$ emission, values for $j^{\prime}=5.5$ are required. $\mathrm{A}_{1}(4) / \mathrm{P}_{1}(6)$ ratio of 0.48 and
Table 5. Experimentally determined fractions of the upper state that decays via each branch within the $\mathrm{OH}(6-2)$ band

\begin{tabular}{llll}
\hline$j^{\prime}$ & $\mathrm{P}_{1}$-branch & $\mathrm{Q}_{1}$-branch & $\mathrm{R}_{1}$-branch \\
\hline 1.5 & $0.434 \pm 0.002$ & $0.548 \pm 0.003$ & \\
2.5 & $0.539 \pm 0.008$ & $0.209 \pm 0.003$ & $0.235 \pm 0.009$ \\
3.5 & $0.587 \pm 0.007$ & $0.101 \pm 0.006$ & $0.299 \pm 0.004$ \\
4.5 & $0.627 \pm 0.008$ & $0.059 \pm 0.002$ & $0.303 \pm 0.011$ \\
5.5 & 0.643 & 0.039 & 0.308 \\
\hline
\end{tabular}

Table 6. Average temperatures derived from the 2791995 and 1996 spectra using the T\&L, Mies and LWR transition probabilities, compared with the values obtained using the experimentally determined relative intensity ratios. Ratios that include $\mathrm{P}_{1}(3)$ do not contribute to the 'weighted sum'. (see text)

\begin{tabular}{llllll}
\hline Ratio & T\&L & \multicolumn{1}{l}{ Mies } & LWR & Experiment \\
\hline $\mathrm{P}_{1}(2) / \mathrm{P}_{1}(3)$ & $222.0 \pm 1.5$ & $211.7 \pm 1.3$ & $204.3 \pm 1.3$ & $200.7 \pm 1.2$ \\
$\mathrm{P}_{1}(2) / \mathrm{P}_{1}(4)$ & $213.5 \pm 0.8$ & $206.2 \pm 0.7$ & $200.3 \pm 0.7$ & $198.8 \pm 0.7$ \\
$\mathrm{P}_{1}(2) / \mathrm{P}_{1}(5)$ & $212.7 \pm 0.7$ & $206.4 \pm 0.7$ & $201.6 \pm 0.6$ & $199.4 \pm 0.6$ \\
$\mathrm{P}_{1}(3) / \mathrm{P}_{1}(4)$ & $209.3 \pm 0.9$ & $203.7 \pm 0.8$ & $198.8 \pm 0.8$ & $198.8 \pm 0.8$ \\
$\mathrm{P}_{1}(3) / \mathrm{P}_{1}(5)$ & $210.5 \pm 0.7$ & $205.3 \pm 0.7$ & $201.3 \pm 0.6$ & $199.4 \pm 0.6$ \\
$\mathrm{P}_{1}(4) / \mathrm{P}_{1}(5)$ & $212.5 \pm 1.0$ & $207.5 \pm 1.0$ & $204.1 \pm 0.9$ & $200.8 \pm 0.9$ \\
Wtd.Sum & 212.5 & 206.6 & 201.7 & \multicolumn{2}{c}{199.5} \\
\hline
\end{tabular}

a $\mathrm{Q}_{1}(5) / \mathrm{P}_{1}(6)$ ratio of 0.06 are selected as consistent with the trends of the measured ratios. Table 5 lists the fraction of the upper state that decays via each transition up to $j^{\prime}=5.5$.

Average temperatures for each of the six possible intensity ratios from the four brightest $\mathrm{P}_{1}$-branch lines from the 2791995 and 1996 spectra are presented in Table 6 for Mies, LWR and T\&L transition probabilities, and for the experimentally determined probabilities. The uncertainties listed in Table 6 are the standard deviations divided by the square-root of the number of spectra. A 'weighted sum' temperature is derived as a sum of the average temperatures determined from the $\mathrm{P}_{1}(2) / \mathrm{P}_{1}(4), \mathrm{P}_{1}(2) / \mathrm{P}_{1}(5)$ and $\mathrm{P}_{1}(4) / \mathrm{P}_{1}(5)$ ratios, weighted inversely as the square of the standard deviation for those ratios. Temperatures derived using the $P_{1}(3)$ intensity are not included in the weighted sum because of contamination by non-thermalized $\mathrm{OH}(5-1) \mathrm{P}_{1}(12)$. As noted by other authors (for example: Turnbull and Lowe, 1989; Greet et al., 1998), the average temperature derived using the T\&L transition probabilities is $6 \mathrm{~K}$ higher than for Mies values and $11 \mathrm{~K}$ higher than for LWR values. The temperature inferred from the experimentally determined 'same-upper-state' line ratios is within the measurement uncertainty of the LWR value.

The average temperatures derived from ratios using the $\mathrm{P}_{1}(3)$ intensity with Mies and $\mathrm{T} \& \mathrm{~L}$ transition probabilities show evidence of the $\mathrm{OH}(5-1) \mathrm{P}_{1}(12)$ contamination. Greet et al. (1998) used this evidence, and $\mathrm{T} \& \mathrm{~L}$ transition probabilities, to estimate the average magnitude of the $\mathrm{OH}(5-1) \mathrm{P}_{1}(12)$ contamination. The average temperatures derived using the LWR transition probabilities show reduced evidence of this contamination, indicating that the magnitude of the contamination estimated in this manner is dependent on the choice of 
transition probabilities. The temperatures inferred from the $P_{1}(2) / P_{1}(3)$ ratio are most sensitive to contamination of $\mathrm{P}_{1}(3)$. That there is no evidence for $\mathrm{OH}(5-1) \mathrm{P}_{1}(12)$ contamination in the averages of the experimentally determined temperatures may result from underestimation of the $\mathrm{Q}_{1}(5)$ contamination of $\mathrm{P}_{1}(2)$. The $j^{\prime}=5.5$ experimental estimates are extrapolations, and the intraband balance of this state (see Table 4) is least certain. If this is the reason for the lack of a signature of the $\mathrm{OH}(5$ 1) $P_{1}(12)$ contamination, then the implied error in the experimentally derived weighted temperature average is of the order of $-1 \mathrm{~K}$. The principal conclusion that the $\mathrm{OH}(6-2)$ rotational temperatures are significantly lower than are determined using Mies and $\mathrm{T} \& \mathrm{~L}$ transition probabilities remains valid.

\section{Conclusions}

$\mathrm{Q}_{1} / \mathrm{P}_{1}$ ratios for $\mathrm{OH}(6-2)$ band lines with $j^{\prime}$ up to 4.5 are measured to be significantly lower than implied by the three published sets of transition probabilities considered.

$\mathrm{R}_{1} / \mathrm{P}_{1}$ ratios for $\mathrm{OH}(6-2)$ band lines with $j^{\prime}$ up to 4.5 are measured to be significantly lower than implied by T\&L and Mies transition probabilities, and lower than LWR values but on the borderline of significance.

Two satellite line ratios are measured. The measured ${ }^{\mathrm{Q}} \mathrm{R}_{12}(1) / \mathrm{P}_{1}(2)$ ratio is consistent with, while ${ }^{\mathrm{P}} \mathrm{Q}_{12}(2) /$ $\mathrm{P}_{1}(2)$ is measured to be $20 \%$ larger than, Goldman (1982) theoretical values.

$\mathrm{OH}(6-2)$ band rotational temperatures inferred from a set of experimentally determined fractions of $j^{\prime}$-state transitions are $2 \mathrm{~K}$ lower than temperatures derived using LWR transition probabilities, $7 \mathrm{~K}$ lower than temperatures derived using Mies values and $13 \mathrm{~K}$ lower than values derived using $T \& L$ values.

It is important to note that no implication can be drawn from our experimental measurements with respect to the absolute values of the transition probabilities. The variation in the absolute values between the three published sets of $\mathrm{OH}(6-2)$ transition probabilities is far greater than the variation in their temperatureinvariant line ratios. T\&L transition probabilities are approximately $350 \%, 395 \%$ and $460 \%$ greater than LWR ratios for the low $j^{\prime}, \mathrm{P}_{1^{-}}, \mathrm{Q}_{1^{-}}$and $\mathrm{R}_{1}$-branch transition probabilities respectively. The Mies transition probabilities are similarly approximately $130 \%, 140 \%$ and $150 \%$ greater than the LWR values. For comparison, the $\mathrm{Q}_{1} / \mathrm{P}_{1}$ and $\mathrm{R}_{1} / \mathrm{P}_{1}$ Mies, T\&L and LWR ratios compared differ by between $3 \%$ and $18 \%$. Our conclusion that LWR OH(6-2) transition probabilities yield rotational temperatures most consistent with experimental measurements provides no direct evidence that the absolute values of LWR transitional probabilities are experimentally preferred.

Acknowledgements. This project has been supported by the Antarctic Science Advisory Committee and the Australian Antarctic Division. The Australian Bureau of Meteorology provided meteorological balloon data from Davis, Antarctica. A.R. Klekociuk provided valuable assistance with discussions and access to programs for deriving $\mathrm{H}_{2} \mathrm{O}$ column densities. Davis station Australian National Antarctic Research Expeditioners from 1995-1997 have supported the collection of these data.

Topical Editor F. Vial thanks M.J. Taylor and F.J. Mulligan for their help in evaluating this paper.

\section{References}

Baker, D. J., and A. T. Stair, Rocket measurements of the altitude distributions of the hydroxyl airglow, Phys. Scr., 37, 611-622, 1988.

Chamberlain, J. W., Physics of the aurora and the airglow, Academic, New York, 1961.

Coxon, J. A., and S. C. Foster, Rotational analysis of hydroxyl vibration-rotation emission bands: molecular constants for $\mathrm{OH}$ $\mathrm{X}^{2} \Pi, 6 \leq v \leq 10$, Can. J. Phys., 60, 41-48, 1982.

Goldman, A., Line parameters for the atmospheric band system of OH, Appl. Opt., 21, 2100-2102, 1982.

Greet, P. A., W. J. R. French, G. B. Burns, P. F. B. Williams, R. P. Lowe, and K. Finlayson, $\mathrm{OH}(6-2)$ spectra and rotational temperature measurements at Davis, Antarctica, Ann. Geophysicae, 16, 77-89, 1998.

Hecht, J. H., S. K. Ramsay Howat, R. L. Waltershied, and J. R. Isler, Observations of variations in airglow emissions during ALOHA-93, Geophys. Res. Lett., 22(20), 2817-2820, 1995.

Hobbs, B. G., I. M. Reid, and P. A. Greet, Mesospheric rotational temperatures determined from the $\mathrm{OH}(6-2)$ emission above Adelaide, Australia, J. Atmos. Terr. Phys., 58(12), 1337-1344, 1996.

Langhoff, S. R., H.-J. Werner, and P. Rosmus, Theoretical transition probabilities for the $\mathrm{OH}$ Meinel system, J. Mol. Spectr., 118, 507-529, 1986.

Longhurst, R. S., Geometrical and physical optics, Longmans, London, 1957.

Lowe, R. P., K. L. Gilbert, and D. N. Turnbull, High-latitude summer observations of the hydroxyl airglow, Planet. Space Sci., 39(9), 1263-1270, 1991.

Mies, F. H., Calculated vibrational transition probabilities of $\mathrm{OH}\left(\mathrm{X}^{2} \Pi\right)$, J. Mol. Spectrosc., 53, 150-180, 1974.

Mulligan, F. J., D. F. Horgan, J. G. Galligan, and E. M. Griffin, Mesopause temperatures and integrated band brightnesses calculated from airglow $\mathrm{OH}$ emissions recorded at Maynooth $\left(53.2^{\circ} \mathrm{N}, 6.4^{\circ} \mathrm{W}\right)$ during 1993, J. Atmos. Terr. Phys., 57(13), 1623-1637, 1995.

Myrabo, H. K., and O. E. Harang, Temperatures and tides in the high-latitude mesopause region as observed in the $\mathrm{OH}$ night airglow emissions, J. Atmos. Terr. Phys., 50(8), 739-748, 1988.

Nelson, Jr., D. D., A. Schiffman, and D. J. Nesbitt, $\mathrm{H}+\mathrm{O}_{3}$ Fourier-transform infrared emission and laser absorption studies of $\mathrm{OH}\left(\mathrm{X}^{2} \Pi\right)$ radical: an experimental dipole moment function and state-to-state Einstein A coefficients, J. Chem. Phys., 93(10), 7003-7019, 1990.

Offermann, D., and R. Gerndt, Upper-mesosphere temperatures from $\mathrm{OH}^{*}$ emissions, Adv. Space Res., 10(12), 217-221, 1990.

Osterbrock, D. E., and A. R. Martel, Sky spectra at a light-polluted site and the use of atomic and $\mathrm{OH}$ sky emission lines for wavelength calibration, Publ. Astron. Soc. Pac., 104, 76-82, 1992.

Osterbrock, D. E., J. P. Fulbright, and T. A. Bida, Night-sky highresolution spectral atlas of $\mathrm{OH}$ and $\mathrm{O}_{2}$ emission lines for Echelle spectrograph wavelength calibration II, Publ. Astron. Soc. Pac., 109, 614-627, 1997.

Osterbrock, D. E., J. P. Fulbright, A. R. Martel, M. J. Keane, S. C. Trader, and G. Basri, Night-sky high-resolution spectral atlas of $\mathrm{OH}$ and $\mathrm{O}_{2}$ emission lines for Echelle spectrograph wavelength calibration, Publ. Astron. Soc. Pac., 108, 277-308, 1996.

Pendleton, W. R., P. J. Espy, and M. R. Hammond, Evidence for non-local-thermodynamic-equilibrium rotation in the $\mathrm{OH}$ nightglow, J. Geophys. Res., 98, 11 567-11 579, 1993.

Rothman, L., R. Gamache, R. Tipping, C. Rinsland, M. Smith, D. Benne, V. Malathy Devi, J. M. Flaud, C. Camy-Peyret, 
A. Perrin, A. Glodman, S. Massie, L. Brown, and R. Toth, The HITRAN molecular data base: Editions of 1991 and 1992, J. Quant. Spectrosc. Radiat. Transfer, 48, 469-507, 1992.

Scheer, J., What can be learned from rotational temperatures derived from ground-based airglow observations about the aeronomy of the southern hemisphere, Adv. Space Res., 16(5), 61-69, 1995.

Sivjee, G. G., Airglow hydroxyl emissions, Planet. Space Sci., 40, 235-242, 1992.

Sivjee, G. G., and R. L. Waltershied, Six-hourly zonally symmetric tidal oscillations of the winter mesopause over the South Pole station, Planet. Space Sci., 42, 447-453, 1994.

Sturman, A. P., and N. J. Tapper, The weather and climate of Australia and New Zealand, Oxford University Press, Melbourne, 1996.
Takahashi, H., and P. P. Batista, Simultaneous measurements of $\mathrm{OH}(9,4),(8,3),(7,2),(6,2)$ and $(5,1)$ bands in the airglow, J. Geophys. Res., 86(A7), 5632-5642, 1981.

Turnbull, D. N., and R. P. Lowe, Vibrational population distribution in the hydroxyl night airglow, Can. J. Phys., 61, 244-250, 1983.

Turnbull, D. N., and R. P. Lowe, New hydroxyl transition probabilities and their importance in airglow studies, Planet. Space Sci., 37, 723-738, 1989.

Viereck, R. A., and C. S. Deehr, On the interaction between gravity waves and the $\mathrm{OH}$ Meinel (6-2) and the $\mathrm{O}_{2}$ Atmospheric (0-1) bands in the polar night airglow, J. Geophys. Res., 94(A5), 5397-5404, 1989. 